\title{
Risk factor for contralateral occult carcinoma in patients with unilateral papillary thyroid carcinoma
}

\author{
Ha Rim Ahn, Sang Yull Kang, Hyun Jo Youn, Sung Hoo Jung \\ Division of Breast and Thyroid Surgery, Department of Surgery, Jeonbuk National University Medical School, Jeonju, Korea
}

Purpose: The extent of surgery necessary in patients with unilateral papillary thyroid carcinoma (PTC) on preoperative radiologic imaging is still in doubt. In this study, we aimed to define risk factors that could be indicators for malignant nodules in the contralateral thyroid lobe.

Methods: We included 438 patients who underwent total thyroidectomy between January 2011 and December 2014 at our institution. In this study, patients were divided into two groups according to the presence of contralateral occult carcinoma identified by postoperative pathological examination. We analyzed the clinicopathologic factors including characteristics of coexistent nodules in the contralateral lobe based on preoperative radiological imaging.

Results: A total of 96 patients (21.9\%) had PTC in the contralateral lobe. There were no significant differences between patients with or without contralateral occult carcinoma with respect to gender, age, primary tumor size, central lymph node metastasis, extrathyroidal extension and stage. The presence of Hashimoto's thyroiditis was an independent predictive factor for contralateral occult carcinoma $(P=0.01)$.

Conclusion: A risk factor for contralateral occult carcinoma in unilateral PTC patients is Hashimoto's thyroiditis. Therefore, more caution is needed when determining optimal surgical methods for PTC patients with Hashimoto's thyroiditis.

Keywords: Papillary thyroid carcinoma, Contralateral, Risk factor

\section{INTRODUCTION}

Papillary thyroid carcinoma (PTC) is the most common histological type of thyroid cancer, accounting for more than $80 \%$ of all thyroid cancer patients [1]. The incidence of PTC is increasing worldwide with the development of imaging techniques and growing interest in health [2]. The primary treatment for thyroid cancer is surgery. PTC patients who underwent unilateral thyroidectomy are known to have lower morbidity than those treated with total or near total thyroidectomy. The 2015 American Thyroid Association management guidelines for adult patients with thyroid nod-

Received: Apr 9, 2020 Revised: May 8, 2020 Accepted: Jun 11, 2020 Correspondence to: Hyun Jo Youn

Department of Surgery, Jeonbuk National University Medical School, 20 Geonji-ro, Deokjin-gu, Jeonju 54907, Korea

Tel: +82-63-250-2389, Fax: +82-63-271-6197

E-mail:yhj0903@jbnu.ac.kr

ORCID: Ha Rim Ahn (https://orcid.org/0000-0002-5187-3712), Sang Yull Kang (https://orcid.org/0000-0002-3970-174X), Hyun Jo Youn (https://orcid.org/00000002-2407-8537), Sung Hoo Jung (https://orcid.org/0000-0001-7058-0870)

Copyright (c) 2020 Korean Society of Surgical Oncology

This is an Open Access article distributed under the terms of the Creative Commons Attribution Non-Commercial License (https://creativecommons.org/licenses/by-nc/4.0) which permits unrestricted non-commercial use, distribution, and reproduction in any medium, provided the original work is properly cited. ules and differentiated thyroid cancer recommends thyroid lobectomy if the tumor size is $4 \mathrm{~cm}$ or less, PTC is unifocal and intrathyroidal and no cervical lymph node metastasis is clinically found $[3,4]$. Lobectomy for PTC patients should be performed only when no contralateral occult carcinoma is detected by preoperative tests. There are cases of PTC where there are two or more separate foci within the thyroid gland. The rate of such multifocal PTCs has been reported to be $18 \%$ to $87 \%$ depending on the accuracy of diagnostic techniques [5]. The rate of preoperatively undiagnosed tumor foci incidentally detected by postoperative pathological analysis has been reported to be $15.8 \%-21.3 \%$ [6,7]. Preoperatively undiagnosed carcinomas in the contralateral lobe may lead to additional surgery due to postoperative remnant disease and may also be associated with regional and distant metastasis [1].

Therefore, this study aimed to identify risk factors for contralateral occult carcinoma based on imaging findings and pathological findings in patients preoperatively diagnosed with unilateral PTC and treated with total thyroidectomy.

\section{METHODS}

We carried out a retrospective review of the medical records of 1,613 PTC patients who underwent total thyroidectomy in the Di- 
vision of Breast and Thyroid Surgery of the Department of Surgery at Jeonbuk National University Hospital from January 1, 2011 to December 31, 2014. Among the patients, patients diagnosed with Korean Thyroid Imaging Reporting and Data System (K-TIRADS) category 4 or higher [8], which are intermediate malignant suspicion categories, in the contralateral lobe of primary tumor by preoperative ultrasonography and neck computed tomography (CT) were excluded from the study. Patients diagnosed with PTCs in both lobes by fine needle aspiration (FNA) and those who underwent completion thyroidectomy were also excluded. Thus, a total of 438 patients were enrolled in this study. All the patients were diagnosed with PTC by preoperative FNA, and preoperative ultrasonography and neck CT were performed to determine the presence or absence of extrathyroidal invasion and central lymph node metastasis. Contralateral occult carcinoma was defined as a lesion which is diagnosed as benign or low suspicion (K-TIRADS categories 2,3) or is not detected (K-TIRADS category 1) by preoperative radiologic tests but diagnosed as malignant postoperatively by final histological examination. And contralateral occult carcinoma also includes occult malignant foci (OMF). Patients were divided into two groups according to the presence or absence of contralateral occult carcinoma based on the results of postoperative histopathologic examination. Then, we examined clinicopathologic factors of each group, such as age, sex, tumor size, the presence of pathologic Hashimoto's thyroiditis (HT), extrathyroidal invasion, the presence of cervical lymph node metastasis, and stage of cancer according to the American Joint Committee on Cancer (AJCC) cancer staging manual, 8th edition [9]. In addition, we also analyzed the association of postoperatively detected contralateral occult carcinoma with the number and size of benign tumors in the ipsilateral and contralateral lobes of PTC by preoperative ultrasonography and neck CT and the number and size of malignant and benign tumors identified by postoperative pathological findings.

Statistical analysis was conducted using R version 3.2.2 (R Foundation for Statistical Computing, Vienna, Austria). Univariate and multivariate logistic regression analyses were performed to investigate the relationship between clinicopathologic characteristics and contralateral occult carcinoma. A P-value $<0.05$ was considered statistically significant. This study was conducted after obtaining the approval of the IRB of Jeonbuk National University Hospital (IRB No. 2019-07-020).

\section{RESULTS}

A total of 438 patients were enrolled in this study and the subjects consisted of 367 females and 71 males. The mean age of the pa- tients at the time of surgery was 49.0 years (range, 15-6 years).

The mean thyroid stimulating hormone (TSH) level was 1.9 $\mathrm{mIU} / \mathrm{L}$, the mean tumor size was $10.3 \mathrm{~mm}$ (range, $5-43 \mathrm{~mm}$ ), and 278 patients (63.4\%) had micro PTC smaller than $1 \mathrm{~cm}$ in size. Central lymph node metastasis was detected in 255 patients (58.2\%), HT in 309 patients (70.5\%) and extrathyroidal extension (ETE) in 250 patients (57\%) (Table 1).

In 96 patients (21.9\%), contralateral occult carcinoma was detected by pathological examination after total thyroidectomy. The mean number of contralateral occult carcinoma was 1.18 (range, $1-3$ ) and the mean size was $3.53 \mathrm{~mm}$ (range, $1-17 \mathrm{~mm}$ ).

Table 1. Demographic characteristics of 438 patients with papillary thyroid carcinoma

\begin{tabular}{|c|c|}
\hline Characteristics & Value $(n=438)$ \\
\hline \multicolumn{2}{|l|}{ Sex } \\
\hline Female & 367 (83.7) \\
\hline Male & $71(16.3)$ \\
\hline \multicolumn{2}{|c|}{ Age at diagnosis (yr) } \\
\hline$<55$ & $305(69.6)$ \\
\hline$\geq 55$ & $133(29.4)$ \\
\hline TSH (mIU/L) & $1.9 \pm 1.5$ \\
\hline \multicolumn{2}{|l|}{ Tumor size $(\mathrm{cm})$} \\
\hline$<1$ & $278(63.4)$ \\
\hline 1 to $<2$ & $121(27.6)$ \\
\hline 2 to $<3$ & $37(8.4)$ \\
\hline$\geq 3$ & $2(0.4)$ \\
\hline \multicolumn{2}{|c|}{ Central lymphnode metastasis } \\
\hline Absent & $255(58.2)$ \\
\hline Present & $183(41.8)$ \\
\hline \multicolumn{2}{|c|}{ Hashimoto's thyroiditis } \\
\hline Absent & $309(70.5)$ \\
\hline Present & $129(29.5)$ \\
\hline \multicolumn{2}{|c|}{ Extrathyroidal extension } \\
\hline Absent & $250(57.0)$ \\
\hline Present & $188(43.0)$ \\
\hline \multicolumn{2}{|l|}{ Stage $e^{a)}$} \\
\hline 1 & 394 (89.9) \\
\hline 2 & 35 (7.9) \\
\hline 3 & $9(2.0)$ \\
\hline \multicolumn{2}{|c|}{ Contralateral lobe tumor K-TIRADS } \\
\hline Category 1 & $119(27.2)$ \\
\hline Category 2 & $74(16.9)$ \\
\hline Category 3 & $245(55.9)$ \\
\hline
\end{tabular}

Values are presented as number $(\%)$ or mean \pm standard deviation. TSH, thyroid stimulating hormone; K-TIRADS, Korean Thyroid Imaging Reporting and Data System.

${ }^{a)}$ American Joint Committee on Cancer (AJCC) cancer staging manual, 8th edition. 
Patients were divided into groups with and without contralateral occult carcinoma to investigate the relationship between clinicopathological characteristics and the presence of contralateral occult carcinoma. Table 2 shows analysis results of the association between clinicopathological characteristics and contralateral occult carcinoma. The clinicopathological characteristic significantly associated with contralateral occult carcinoma was the presence of HT $(P=0.01)$. However, there were no statistically significant differences between the two groups in gender, age, TSH level, tumor

Table 2. Clinicopathologic characteristics in relation to contralateral occult carcinoma in 438 patients with papillary thyroid carcinoma

\begin{tabular}{|c|c|c|c|}
\hline Characteristics & $\begin{array}{l}\text { Contralateral } \\
\text { occult } \\
\text { carcinoma (-) } \\
(n=342)\end{array}$ & $\begin{array}{l}\text { Contralateral } \\
\text { occult } \\
\text { carcinoma }(+) \\
\quad(n=96)\end{array}$ & P-value \\
\hline Sex & & & 0.98 \\
\hline Female & $286(83.6)$ & $81(84.4)$ & \\
\hline Male & $56(16.4)$ & $15(15.6)$ & \\
\hline Age at diagnosis (yr) & & & 1.00 \\
\hline$<55$ & $238(69.6)$ & $67(69.8)$ & \\
\hline$\geq 55$ & $104(30.4)$ & $29(30.2)$ & \\
\hline TSH (mlU/L) & $1.9 \pm 1.4$ & $1.9 \pm 1.8$ & 0.95 \\
\hline Tumor size $(\mathrm{cm})$ & & & 0.06 \\
\hline$<1$ & $226(66.1)$ & $52(54.2)$ & \\
\hline 1 to $<2$ & $85(24.9)$ & $36(37.5)$ & \\
\hline 2 to $<3$ & $30(8.8)$ & $7(7.3)$ & \\
\hline$\geq 3$ & $1(0.3)$ & $1(1.0)$ & \\
\hline Central lymph node metastasis & & & 1.00 \\
\hline Absent & $199(58.2)$ & $56(58.3)$ & \\
\hline Present & $143(41.8)$ & $40(41.7)$ & \\
\hline Hashimoto's thyroiditis & & & 0.01 \\
\hline Absent & $252(73.7)$ & $57(59.4)$ & \\
\hline Present & $90(26.3)$ & $39(40.6)$ & \\
\hline Extrathyroidal extension & & & 0.76 \\
\hline Absent & $197(57.6)$ & $53(55.2)$ & \\
\hline Present & $145(42.4)$ & $43(44.8)$ & \\
\hline Stage $e^{a)}$ & & & 0.77 \\
\hline 1 & 306 (89.5) & $88(91.7)$ & \\
\hline 2 & $29(8.5)$ & $6(6.2)$ & \\
\hline 3 & $7(2.0)$ & $2(2.1)$ & \\
\hline Contralateral lobe tumor K-TIRADS & & & 0.06 \\
\hline Category 1 & $98(28.7)$ & $21(21.9)$ & \\
\hline Category 2 & $63(18.4)$ & $11(11.5)$ & \\
\hline Category 3 & $181(52.9)$ & $64(66.7)$ & \\
\hline
\end{tabular}

Values are presented as number (\%) or mean \pm standard deviation.

TSH, thyroid stimulating hormone; K-TIRADS, Korean Thyroid Imaging Reporting and Data System.

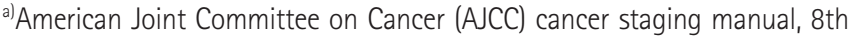
edition. size, central lymph node metastasis, ETE, AJCC stage, and K-TIRADS category of contralateral lobe tumor.

The cases without ipsilateral multifocal tumors were $172 \mathrm{pa}-$ tients (50.3\%) and 42 patients (43.8\%) in the group without contralateral occult carcinoma and the group with contralateral occult carcinoma, respectively, showing that ipsilateral multifocality was not associated with contralateral occult carcinoma. The mean number of cancer lesions in the ipsilateral lobe detected by preoperative ultrasonography was 1.34 (range, 1-6). In both groups, the mean number of benign nodules in the ipsilateral lobe was 0.7 (range, 0-9). Preoperative examination revealed multifocality in the contralateral lobe in 244 patients (71.3\%) of the group without contralateral occult carcinoma and in 75 patients (78.1\%) of the group with contralateral occult carcinoma, showing that there was no significant difference between the two groups $(\mathrm{P}=0.23)$.

Among patients in whom contralateral occult carcinoma was detected, 21 patients (21.9\%) were found to have OMF. The number of contralateral tumors classified as K-TIRADS category 3 or lower was 1.5 and 1.6 in the group without contralateral PTC and the group with contralateral occult carcinoma, respectively, indicating that there were no statistically significant differences between the two groups. In addition, the mean tumor size of the contralateral nodules categorized as K-TIRADS category 3 or lower

Table 3. Preoperative multifocality and tumor characteristics in relation to contralateral occult carcinoma in 438 patients with PTC

\begin{tabular}{|c|c|c|c|}
\hline Variable & $\begin{array}{c}\text { Contralateral } \\
\text { occult PTC }(-) \\
(n=342)\end{array}$ & $\begin{array}{l}\text { Contralateral } \\
\text { occult PTC }(+) \\
(n=96)\end{array}$ & P-value \\
\hline Ipsilateral lobe multifocality & & & 0.30 \\
\hline Absent & $172(50.3)$ & $42(43.8)$ & \\
\hline Present & $170(49.7)$ & $54(56.2)$ & \\
\hline Ipsilateral cancer count & & & 0.15 \\
\hline 1 & $267(78.1)$ & $64(66.7)$ & \\
\hline 2 & $53(15.5)$ & $24(25.0)$ & \\
\hline 3 & $17(5.0)$ & $6(6.2)$ & \\
\hline 4 & $2(0.6)$ & $2(2.1)$ & \\
\hline 5 & $2(0.6)$ & 0 & \\
\hline 6 & $1(0.3)$ & 0 & \\
\hline Ipsilateral benign tumor count & $0.7 \pm 1.2$ & $0.7 \pm 1.2$ & 0.74 \\
\hline Contralateral lobe multifocality & & & 0.23 \\
\hline Absent & $98(28.7)$ & $21(21.9)$ & \\
\hline Present & $244(71.3)$ & $75(78.1)$ & \\
\hline Contralateral benign tumor count & $1.5 \pm 1.5$ & $1.6 \pm 1.4$ & 0.66 \\
\hline Contralateral benign tumor size $(\mathrm{mm})$ & $4.5 \pm 5.1$ & $4.4 \pm 4.0$ & 0.89 \\
\hline Bilateral tumor count & $3.5 \pm 2.5$ & $3.7 \pm 2.2$ & 0.58 \\
\hline
\end{tabular}

Values are presented as number (\%) or mean \pm standard deviation.

PTC, papillary thyroid carcinoma. 
Table 4. Multivariate analysis for risk factor of contralateral occult carcinoma

\begin{tabular}{lccc}
\hline Risk factor & OR & $95 \% \mathrm{Cl}$ & P-value \\
\hline Ipsilateral lobe multifocality & 1.30 & $0.82-2.05$ & 0.25 \\
Contralateral lobe multifocality & 1.33 & $0.78-2.24$ & 0.28 \\
Hashimoto's thyroiditis & 1.91 & $1.19-3.07$ & 0.01 \\
Extrathyroidal extension & 1.10 & $0.69-1.73$ & 0.67 \\
Lymph node metastasis & 0.99 & $0.62-1.57$ & 0.97 \\
Primary tumor size & 1.84 & $1.12-3.01$ & 0.12 \\
\hline
\end{tabular}

$\mathrm{OR}$, odds ratio; $\mathrm{Cl}$, confidence interval.

was $4.5 \mathrm{~mm}$ and $4.4 \mathrm{~mm}$ in the without contralateral occult carcinoma group and the with contralateral occult carcinoma group, respectively; as such, there were no statistically significant differences between the two groups. Furthermore, the total number of thyroid nodules detected preoperatively was 3.5 and 3.7 , respectively, so there was no statistically significant difference between the two groups (Table 3).

Four out of 119 patients (3.4\%) who were in K-TIRADS category 1 had benign nodule in the contralateral lobe, and OMF in the contralateral lobe was in 21 patients (17.6\%). Of the 74 patients who were in K-TIRADS category 2, 37 patients (50\%) had benign nodule in the contralateral lobe, one patient (1.4\%) had cancer and concurrent benign nodule, and 10 patients (13.6\%) had cancer. Of the 245 patients who were in K-TIRADS category 3, 133 patients (54.3\%) had benign nodule in the contralateral lobe, nine patients (3.7\%) had cancer and concurrent benign nodule, and 55 patients (22.4\%) had cancer.

Multivariate logistic regression analysis showed that HT is a risk factor for contralateral occult carcinoma and that primary carcinoma size, central lymph node metastasis, ETE, and multifocality were not associated with an increase in contralateral occult carcinoma (Table 4).

\section{DISCUSSION}

The American Thyroid Association guidelines [4] recommends total thyroidectomy for thyroid cancer larger than $4 \mathrm{~cm}$ in size, but the use of total thyroidectomy still remains controversial for thyroid cancer with a size of $4 \mathrm{~cm}$ or less, and the optimal extent of surgical treatment for PTC is still under debate [4-6]. In this study, we investigated whether primary tumor characteristics such as the size of primary tumor, multifocality, central lymph node metastasis, HT, and ETE, which are factors affecting the extent of surgical resection, are associated with contralateral occult carcinoma. We also analyzed the association of the size and number of benign and low malignant nodules in the contralateral lobe with contralateral occult carcinoma.

Pitt et al. reported that $30 \%$ of patients with primary tumor of 1 $\mathrm{cm}$ or larger and $26 \%$ of patients with primary tumor smaller than $1 \mathrm{~cm}$ were found to have PTC in the contralateral lobe. It has been reported that primary tumor size was not significantly related to the presence of contralateral occult carcinoma $[1,10]$. In agreement with those findings, in the present study, contralateral occult carcinoma was present in $27.5 \%$ of patients with primary tumor with a size of $1 \mathrm{~cm}$ or greater and in $23.0 \%$ of patients with primary tumor smaller than $1 \mathrm{~cm}$, so primary cancer size was not a significant predictive factor for the presence of PTC in the contralateral lobe.

Consistent with the results of Jo et al. [11], who reported that the mean size of contralateral OMF was $2 \mathrm{~mm}$ (range, $1-3 \mathrm{~mm}$ ), in this study, the mean size of contralateral OMF was $1.89 \mathrm{~mm}$ (range, 1-6.6 mm) and the mean size of contralateral occult carcinoma was $2.33 \mathrm{~mm}$. In the 2000s, the development of ultrasound enabled us to detect thyroid nodules with a size of $2 \mathrm{~mm}$ or greater [12]. However, among contralateral occult carcinomas, lesions smaller than $2 \mathrm{~mm}$ are still difficult to detect by ultrasonography. Therefore, OMF is likely to be identified only in pathologic reports, though the development of ultrasound technology is expected to make it possible to detect OMF by ultrasonography.

In the literature, the rate of multifocality of PTC ranges from $15 \%$ to $43 \%$ [13,14]. Kim et al. [15] reported that cancer multifocality of the ipsilateral lobe was a predictive factor for additional cancer in the contralateral lobe. Another study suggested that the presence of a benign nodule in the contralateral lobe may be an independent predictive factor for contralateral occult carcinoma in patients diagnosed with unilateral papillary thyroid microcarcinoma by preoperative ultrasonography [16]. However, in this study, multifocality including cancers and benign nodules in the primary tumor lobe was not significantly associated with the presence of contralateral occult carcinoma.

In this study, we investigated whether there are significant differences between the groups with and without contralateral occult carcinoma in the multifocality and size of contralateral lobe nodules classified as the K-TIRADS category 1 for no nodule, category 2 for benign (malignancy risk $<3 \%$ ) and category 3 for low suspicion (malignancy risk 3\%-15\%) according to the K-TIRADS categories presented by the Korean Society of Thyroid Radiology. These findings are in contrast to the results of many previous studies that reported that multifocality is a risk factor for contralateral PTC $[11,15,17,18]$. This discrepancy in study findings may be attributed to the fact that the number of patients enrolled in this study was not sufficient to determine the significance of multifocality.

However, there were limitations on one-to-one matching of le- 
sions preoperatively categorized as benign or low malignancy with lesions diagnosed as cancers by pathological examination. There are two main reasons for this problem. First, it was difficult to regard the lesions identified by preoperative ultrasound as identical to the lesions detected by pathological examination because the sizes of lesions measured by ultrasound preoperatively may become different according to the ultrasound views. Second, there were cases where a new lesion was detected at a different location in patients with benign lesions. These reasons are thought to be explained by the fact that the K-TIRADS categories of contralateral lobe nodules evaluated preoperatively were not significantly associated with the presence of contralateral occult carcinoma in this study.

The incidence of ETE in well-differentiated thyroid cancer reported in previous studies varies widely from $5 \%$ to $34 \%$ and it is known to be an important adverse prognostic factor [19-21]. Pitt et al. [1] reported that ETE of primary carcinoma smaller than $1 \mathrm{~cm}$ was not a risk factor for contralateral occult carcinoma. In a study by Jo et al. [11] on the risk factors for OMF in the contralateral lobe, ETE was present in $45 \%$ of patients without OMF and in $44.3 \%$ of patients with OMF, and there was no significant difference between the two groups. Similarly, in this study, ETE was found in $42.4 \%$ of patients without contralateral occult carcinoma and in $44.8 \%$ of patients with contralateral occult carcinoma; There was also no significant difference between the two groups $(\mathrm{P}=0.76)$.

The true incidence of contralateral PTC is difficult to estimate in cases where total thyroidectomy is not performed [22]. The incidence of contralateral PTC identified in the specimens of patients who underwent $\mathrm{CT}$ or total thyroidectomy reported in the literature ranges from $13 \%$ to $56 \%$, and, in this study, contralateral PTC was detected in $21.9 \%$ of patients [1,3,23]. Multivariate analysis of primary tumor characteristics showed that only the presence of HT was a significant risk factor for contralateral occult carcinoma. The association between HT and differentiated thyroid carcinoma has been studied in many previous studies [24]. Segal et al. [25] reported that HT is not a premalignant condition and it delays the growth and development of thyroid carcinoma. In contrast, Di Pasquale et al. [26] reported the increased incidence of papillary carcinomas associated with HT. In this study, the incidence of contralateral occult carcinoma was significantly higher in patients with HT than in patients without HT $(\mathrm{P}<0.01)$. This finding is similar to the results of Bradly et al. [24] who reported that HT is a risk factor for incidental PTC. Therefore, contralateral lobe evaluation should be conducted more carefully in patients with HT, and total thyroidectomy may be considered as a treatment method to reduce potential morbidity such as remnant cancer, recurrence, and additional operations. If this study were analyzed with HT di- agnosed with preoperative imaging or laboratory tests, it would have been useful in clinical practice. However, the readings were inconsistent because preoperative imaging was performed by many sonographers. In addition, preoperative antibody screening tests were limited because HT confirmed by laboratory tests were not covered by medical insurance. Therefore, unfortunately, we analyzed the data with pathologic HT.

The 10-year survival rate of PTC patients is reported to be more than $90 \%$ and PTC generally shows an excellent prognosis [10]. In the present study, among 438 patients, 10 patients became lost to follow-up, six patients had lymph node metastasis, and one patient had lung metastasis for 5 years after surgery. Total thyroidectomy may result in postoperative morbidity, including hypoparathyroidism in $6 \%$ of patients, recurrent laryngeal nerve injury in $1 \%$ of patients, and transient hypocalcemia [27]. PTC is a slow growing tumor and generally shows better prognosis compared to other histological types of thyroid cancer. In addition, thyroid lobectomy preserves thyroid function and has the advantage of the patient not needing lifelong thyroid hormone replacement. Therefore, thyroid lobectomy should be considered as a treatment option in unilateral PTC patients without HT.

This study has further limitations in that this is a single institutional study conducted with patients who underwent diagnosis and surgery at our medical institution, a tertiary general hospital, from 2011 to 2014, and that it is also a retrospective study. In addition, this study has limitations regarding the accuracy of preoperative thyroid ultrasonography because it was performed by an experienced specialist and a resident in the department of radiology of our medical institution. Therefore, the quality of research should be enhanced by conducting a multi-institutional study with more patients and an increase in the accuracy of ultrasound examination.

In the present study, among patients preoperatively diagnosed with unilateral PTC, 96 patients (21.9\%) were found to have contralateral occult carcinoma. Among clinicopathologic characteristics, only HT was found to be a risk factor for contralateral occult carcinoma. Therefore, surgical methods for PTC patients with HT should be determined with more caution.

\section{CONFLICT OF INTEREST}

No potential conflict of interest relevant to this article was reported.

\section{REFERENCES}

1. Pitt SC, Sippel RS, Chen H. Contralateral papillary thyroid cancer: does size matter? Am J Surg 2009;197:342-7. 
2. Mazeh H, Samet Y, Hochstein D, Mizrahi I, Ariel I, Eid A, et al. Multifocality in well-differentiated thyroid carcinomas calls for total thyroidectomy. Am J Surg 2011;201:770-5.

3. Pasieka JL, Thompson NW, McLeod MK, Burney RE, Macha M. The incidence of bilateral well-differentiated thyroid cancer found at completion thyroidectomy. World J Surg 1992;16:711-7.

4. Haugen BR, Alexander EK, Bible KC, Doherty GM, Mandel SJ, Nikiforov YE, et al. 2015 American Thyroid Association management guidelines for adult patients with thyroid nodules and differentiated thyroid cancer: the American Thyroid Association guidelines task force on thyroid nodules and differentiated thyroid cancer. Thyroid 2016;26:1-133.

5. So YK, Kim MW, Son YI. Multifocality and bilaterality of papillary thyroid microcarcinoma. Clin Exp Otorhinolaryngol 2015;8:1748.

6. Koo BS, Lim HS, Lim YC, Yoon YH, Kim YM, Park YH, et al. Occult contralateral carcinoma in patients with unilateral papillary thyroid microcarcinoma. Ann Surg Oncol 2010;17:1101-5.

7. Zhou YL, Zhang W, Gao EL, Dai XX, Yang H, Zhang XH, et al. Preoperative BRAF mutation is predictive of occult contralateral carcinoma in patients with unilateral papillary thyroid microcarcinoma. Asian Pac J Cancer Prev 2012;13:1267-72.

8. Shin JH, Baek JH, Chung J, Ha EJ, Kim JH, Lee YH, et al. Ultrasonography diagnosis and imaging-based management of thyroid nodules: revised Korean Society of Thyroid Radiology consensus statement and recommendations. Korean J Radiol 2016;17:370-95.

9. Amin MB, Edge S, Greene F, Byrd DR, Brookland RK, Washington MK, et al. AJCC cancer staging manual. 8th ed. New York, NY: Springer; 2018.

10. Grigsby PW, Reddy RM, Moley JF, Hall BL. Contralateral papillary thyroid cancer at completion thyroidectomy has no impact on recurrence or survival after radioiodine treatment. Surgery 2006;140: 1043-9.

11. Jo SW, Park HK, Ha TK. Prediction of contralateral occult malignant nodule in patients with unilaterally confined papillary thyroid carcinomas. J Endocr Surg 2018;18:191-8.

12. Kim MJ, Yi KH. Thyroid nodules with discordant results of ultrasonographic and fine-needle aspiration findings. J Korean Med Assoc 2018;61:225-31.

13. Kucuk NO, Tari P, Tokmak E, Aras G. Treatment for microcarcinoma of the thyroid: clinical experience. Clin Nucl Med 2007;32:27981.

14. Ito Y, Uruno T, Nakano K, Takamura Y, Miya A, Kobayashi K, et al. An observation trial without surgical treatment in patients with papillary microcarcinoma of the thyroid. Thyroid 2003;13:381-7.

15. Kim ES, Kim TY, Koh JM, Kim YI, Hong SJ, Kim WB, et al. Com- pletion thyroidectomy in patients with thyroid cancer who initially underwent unilateral operation. Clin Endocrinol (Oxf) 2004;61: 145-8.

16. Lee YC, Eun YG, Sohn YM, Rhee SY, Hong IK, Chon S, et al. Predictive factors for occult contralateral carcinoma in patients with unilateral papillary thyroid microcarcinoma by preoperative ultrasonographic and pathological features. World J Surg 2015;39:173641.

17. Molnar C, Molnar S, Bedekovics J, Mokanszki A, Gyory F, Nagy E, et al. Thyroid carcinoma coexisting with Hashimoto's thyreoiditis: clinicopathological and molecular characteristics clue up pathogenesis. Pathol Oncol Res 2019;25:1191-7.

18. Lee KJ, Cho YJ, Kim JG, Lee DH. How many contralateral papillary thyroid carcinomas can be missed? World J Surg 2013;37:7805.

19. Hu A, Clark J, Payne RJ, Eski S, Walfish PG, Freeman JL. Extrathyroidal extension in well-differentiated thyroid cancer: macroscopic vs microscopic as a predictor of outcome. Arch Otolaryngol Head Neck Surg 2007;133:644-9.

20. Ortiz S, Rodriguez JM, Soria T, Perez-Flores D, Pinero A, Moreno J, et al. Extrathyroid spread in papillary carcinoma of the thyroid: clinicopathological and prognostic study. Otolaryngol Head Neck Surg 2001;124:261-5.

21. Andersen PE, Kinsella J, Loree TR, Shaha AR, Shah JP. Differentiated carcinoma of the thyroid with extrathyroidal extension. Am J Surg 1995;170:467-70.

22. Bilimoria KY, Bentrem DJ, Ko CY, Stewart AK, Winchester DP, Talamonti MS, et al. Extent of surgery affects survival for papillary thyroid cancer. Ann Surg 2007;246:375-84.

23. Schonberger J, Marienhagen J, Agha A, Rozeboom S, Bachmeier E, Schlitt $\mathrm{H}$, et al. Papillary microcarcinoma and papillary cancer of the thyroid $<$ or $=1 \mathrm{~cm}$ : modified definition of the $\mathrm{WHO}$ and the therapeutic dilemma. Nuklearmedizin 2007;46:115-20.

24. Bradly DP, Reddy V, Prinz RA, Gattuso P. Incidental papillary carcinoma in patients treated surgically for benign thyroid diseases. Surgery 2009;146:1099-104.

25. Segal K, Ben-Bassat M, Avraham A, Har-El G, Sidi J. Hashimoto’s thyroiditis and carcinoma of the thyroid gland. Int Surg 1985;70: 205-9.

26. Di Pasquale M, Rothstein JL, Palazzo JP. Pathologic features of Hashimoto's-associated papillary thyroid carcinomas. Hum Pathol 2001;32:24-30.

27. Pearce EN, Braverman LE. Papillary thyroid microcarcinoma outcomes and implications for treatment. J Clin Endocrinol Metab 2004;89:3710-2. 